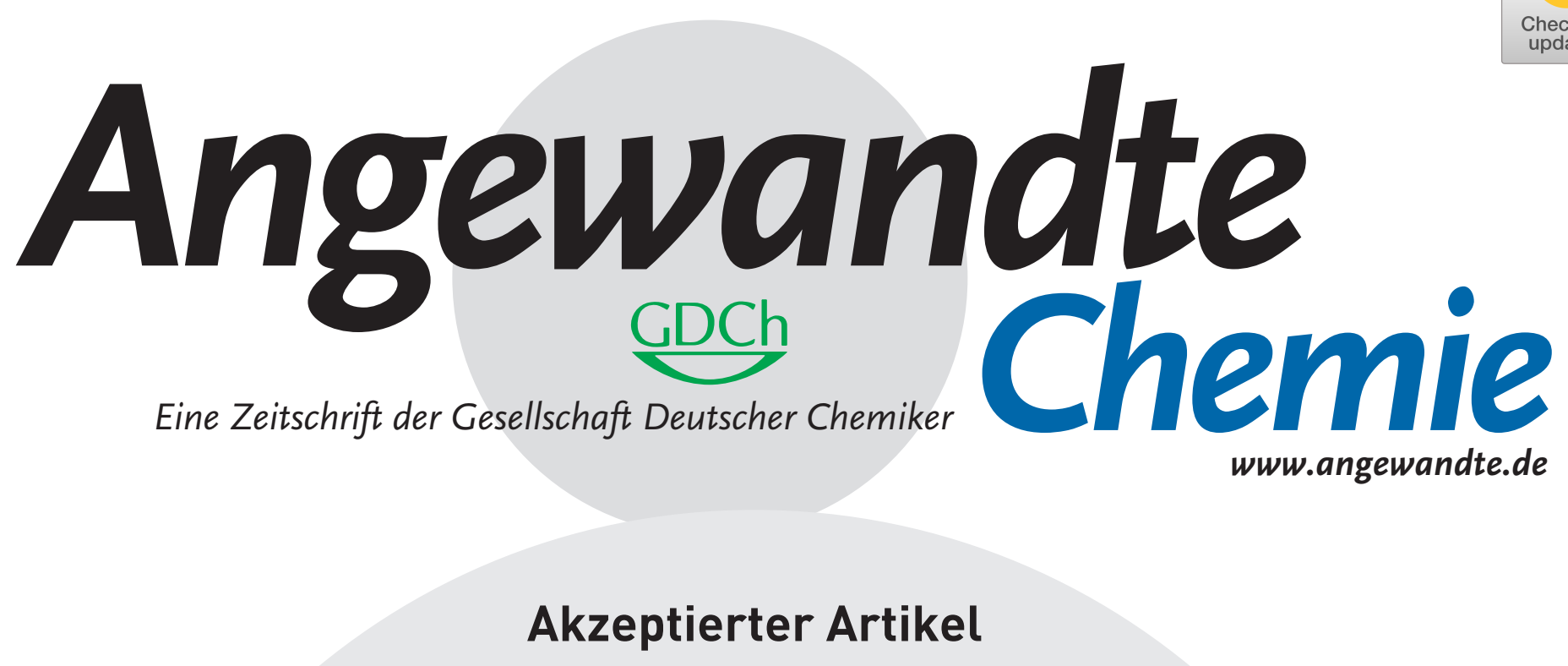

Titel: Fuel-responsive allosteric DNA-based aptamers for the transient release of ATP and cocaine

Autoren: Erica Del Grosso, Giulio Ragazzon, Leonard Prins, and Francesco Ricci

Dieser Beitrag wurde nach Begutachtung und Überarbeitung sofort als "akzeptierter Artikel" (Accepted Article; AA) publiziert und kann unter Angabe der unten stehenden Digitalobjekt-Identifizierungsnummer (DOI) zitiert werden. Die deutsche Übersetzung wird gemeinsam mit der endgültigen englischen Fassung erscheinen. Die endgültige englische Fassung (Version of Record) wird ehestmöglich nach dem Redigieren und einem Korrekturgang als Early-View-Beitrag erscheinen und kann sich naturgemäß von der AA-Fassung unterscheiden. Leser sollten daher die endgültige Fassung, sobald sie veröffentlicht ist, verwenden. Für die AA-Fassung trägt der Autor die alleinige Verantwortung.

Zitierweise: Angew. Chem. Int. Ed. 10.1002/anie.201812885 Angew. Chem. 10.1002/ange.201812885

Link zur VoR: http://dx.doi.org/10.1002/anie.201812885 http://dx.doi.org/10.1002/ange.201812885 


\title{
Fuel-responsive allosteric DNA-based aptamers for the transient release of ATP and cocaine
}

\author{
Erica Del Grosso, ${ }^{1}$ Giulio Ragazzon, ${ }^{2}$ Leonard Prins, ${ }^{2,{ }^{*}}$ Francesco Ricci ${ }^{1,}$
}

\begin{abstract}
Allostery is generally considered as a thermodynamic equilibrium phenomenon. In contrast to this, we show here that this mechanism offers a key strategy to rationally design out-ofequilibrium synthetic devices. We demonstrate this by engineering allosteric DNA-based nanodevices for the transient load and release of small organic molecules. To demonstrate the versatility and generality of our approach we have employed two model DNAbased aptamers that bind ATP and cocaine through a target-induced conformational change. We have rationally re-engineered these aptamers so that their affinity towards their specific target is controlled by a DNA sequence acting as an allosteric inhibitor. The use of an enzyme that specifically cleaves the inhibitor only when it is bound to the aptamer generates a transient allosteric control that leads to the temporal release of ATP or cocaine from the aptamers. Our approach confirms how the programmability and predictability of nucleic acids make synthetic DNA/RNA the perfect candidate material to re-engineer synthetic receptors that can undergo chemical fuel-triggered release of different kinds of small molecule cargoes (ATP and cocaine) and to rationally design non-equilibrium systems. Moreover, our study illustrates the potential of transient allosteric regulation as a tool to control the functions of synthetic dissipative devices.
\end{abstract}

Life is a non-equilibrium phenomenon. Indeed, Nature exploits chemical energy to drive and regulate reactions away from equilibrium. ${ }^{[1-3]}$ This allows to control cell metabolism, power molecular machinery and control structure formation, leading to adaptive systems that can be temporally and spatially controlled. Although synthetic systems for transient structure formation, ${ }^{[4-14]}$ signal generation, ${ }^{[15,16]}$ and cargo delivery ${ }^{[17]}$ have been developed, allosteric receptors that display transient behavior have so far received limited attention. ${ }^{[1,2,18-23]}$ This marks a strong contrast with the central role played by allostery in all living systems. ${ }^{[24]}$ Allostery, often referred as the "second secret of life", ${ }^{[25]}$ is in fact a widespread mechanism employed by Nature to control the activity of biomolecular receptors, like proteins and enzymes, in a highly controllable way. Despite allostery being generally studied as a thermodynamic equilibrium phenomenon, here we will show that this mechanism offers a key strategy for the temporal regulation of chemical

[*] E. Del Grosso, Prof. F. Ricci

Dipartimento di Scienze e Tecnologie Chimiche

University of Rome Tor Vergata,

Via della Ricerca Scientifica, Rome 00133 (Italy)

E-mail: francesco.ricci@uniroma2.it

G. Ragazzon, L. J. Prins

Department of Chemical Sciences, University of Padua, Via Marzolo 1, 35131 Padua, Italy

Email: leonard.prins@unipd.it

[*] This work was supported by the European Research Council, ERC (project no. 336493) (F.R.), by the Associazione Italiana per la Ricerca sul Cancro, AIRC (project no. 14420) (F.R.), by the Italian Ministry of Health (project no. GR-2010-2317212) (F.R.) and by the Italian Ministry of University and Research (Project of National Interest, PRIN, 2012CTAYSY) (F.R.).

Supporting information for this article is given via a link at the end of the document. signals.

To this aim, we turned our attention to aptamers, which are in-vitro selected DNA and RNA sequences able to bind a variety of targets ranging from metal ions, small molecules, proteins, to whole live cells, viruses and bacteria, with high affinity and specificity. ${ }^{[26,27]}$ Several groups have reported and rationallydesigned aptamer-based allosteric systems. ${ }^{[28-32]}$ However, to the best of our knowledge, all these allosteric aptamers operate under straightforward thermodynamic control (Figure 1a, top): i.e. the affinity of the aptamer towards a specific ligand is shifted towards higher ligand concentrations (Figure 1b) upon the binding of an allosteric effector (e.g. in this case an inhibitor or fuel) to a site distal from the ligand's binding site. The characteristic kinetic profile for this kind of process (Figure 1c) shows that after equilibrium has been reached the addition of more fuel has no effect, because all cargo has already been released.

We demonstrate here that transient allosteric regulation can be achieved if the allosteric inhibitor (fuel) is specifically degraded once bound to the aptamer, for example through the action of an enzyme that is present in the system (see Figure $1 \mathrm{a}$, bottom). In this case the aptamer will work "under dissipative conditions" ${ }^{21}$ and can restore its original ligand affinity in a timedependent fashion (Figure 1d) with an entirely different kinetic profile (Figure 1e). Importantly, after consumption of the effector, the aptamer returns to the original state and the addition of new fuel can initiate a new cycle.

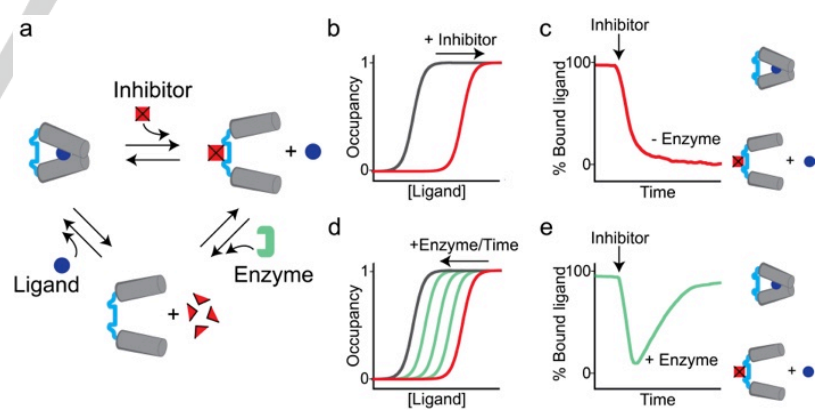

Figure 1. The affinity of an allosterically regulated receptor for its specific ligand can be shifted towards higher concentrations through the binding of an allosteric inhibitor (or fuel) to a site distal from the ligand's binding site (a-b). At a fixed ligand concentration, the allosteric effect of the inhibitor causes a conformational switch of the receptor from the high-affinity state (left) to the low-affinity state (right), leading to the release of the ligand (c). In the presence of an enzyme able to degrade the allosteric inhibitor when bound to the receptor (a), such effect becomes transient and the receptor restores its original affinity for the ligand over time (d) and will thus be able to re-load the ligand in a time-dependent fashion (e).

As a first model system to demonstrate the transient load and release of a small molecule by a DNA-based aptamer under dissipative conditions, we choose the well-characterized ATPbinding aptamer. ${ }^{[33]}$ This is a 25-base DNA sequence able to bind ATP through a binding-induced conformational change mechanism. We have re-engineered this aptamer so that its affinity for ATP could be controlled by an external allosteric effector. To do so we have split the ATP-binding aptamer 
sequence into two functional units connected by an 18-base linker strand which served as the allosteric site (Figures 2a, S1). As the allosteric inhibitor we designed an 18-base DNA-strand that, upon binding to the linker domain, causes a conformational change that negatively affects the affinity of the aptamer for ATP (Figure 2a). Of note, the linker strand and the inhibitor strand are designed to form a ds-DNA sequence specifically recognized by the enzyme Nt.BsmAl. This enzyme is thus able to bind to this sequence and selectively promote the cleavage of the DNA allosteric inhibitor, which restores the original affinity of the ATPbinding aptamer (Figure 2a). In order to follow the ATP loading/release we have labeled the aptamer ends with a fluorophore/quencher-pair.

To verify the functionality of our system, we started with binding studies that revealed the capability of the re-engineered aptamer to bind ATP $\left(K_{d \_A T P}=2.2 \pm 0.1 \times 10^{-4} \mathrm{M}\right)$. This affinity is, as expected for a split aptamer, slightly poorer than that reported for the original aptamer $\left(K_{d}=1.6 \pm 0.1 \times 10^{-5} \mathrm{M}\right)^{[34]}$ (Figure $2 \mathrm{~b}$, black curve). Importantly, upon binding of the DNA inhibitor complementary to the linker domain, the aptamer undergoes a conformational change that causes a 20 -fold decrease in the apparent affinity for ATP ( $\left.\mathrm{K}_{\mathrm{d} \_A T P+i n h i b i t o r}=4.6 \pm 0.9 \times 10^{-3} \mathrm{M}\right)$ (Figure $2 \mathrm{~b}$, red curve). The same binding study performed on a sample exposed to the nickase Nt.BsmAl revealed that after inhibitor cleavage the original affinity of the receptor is nearly completely restored ( $\mathrm{K}_{\mathrm{d} \_A T P+e n z y m e}=5 \pm 1 \times 10^{-4} \mathrm{M}$ ) (Figure $2 \mathrm{~b}$, green curve). This system seems therefore adequate for the transient release of ATP from the receptor upon addition of an inhibitor strand under dissipative conditions. The behavior was indeed confirmed with time-course experiments. In the absence of the enzyme a significant signal increase is observed upon the addition of the DNA-inhibitor complementary to the linker portion, indicating the opening of the receptor and, consequently, the release of ATP (Figure S2). Instead, in the presence of the nickase, the signal increase, associated with ATP release, is followed by a gradual decrease to the initial value, indicating the re-loading of ATP (Figure 2c, black curve). The dissipative behavior is confirmed by a native PAGE electrophoresis experiment that shows the capability of the nickase to selectively hydrolyze the DNA-inhibitor sequence and to restore the original affinity of the receptor for ATP (Figure S3). Importantly, the enzyme acts on the DNA inhibitor only when it is bound to the ATP-aptamer, implying that inhibitor consumption is intimately connected to the formation of the active complex (Figure S4).

Transientness is also strongly enzyme-specific thanks to the high substrate-selectivity of the nickase enzyme. We demonstrated this by employing $\mathrm{RNase}-\mathrm{H}$, an endonuclease able to bind a DNA/RNA heteroduplex and to selectively hydrolyze the RNA-strand. In the presence of this enzyme, the addition of the DNA inhibitor strand only results in the release of ATP without the observation of any dissipative behavior (Figure $2 \mathrm{c}$, red curve).

Energy dissipation can be controlled by varying both the enzyme and inhibitor concentration. To demonstrate this we have first performed time-course experiments in which a constant concentration of DNA inhibitor $\left(1.5 \times 10^{-9} \mathrm{M}\right)$ was added in the presence of different concentrations of Nt.BsmAl (Figure 2d). The half-life of the released ATP decreased from 100 to 20 minutes upon increasing the concentration of the Nt.BsmAl from 30 to $150 \mathrm{U} / \mathrm{ml}$ (Figure S5). In a similar experiment we kept a constant amount of nickase enzyme and added different concentrations of the inhibitor strand. The half-life of the released ATP increased from 12 to 37 minutes upon increasing the inhibitor concentration from $5 \times 10^{-9}$ to $40 \times 10^{-9} \mathrm{M}$ (Figure S6).
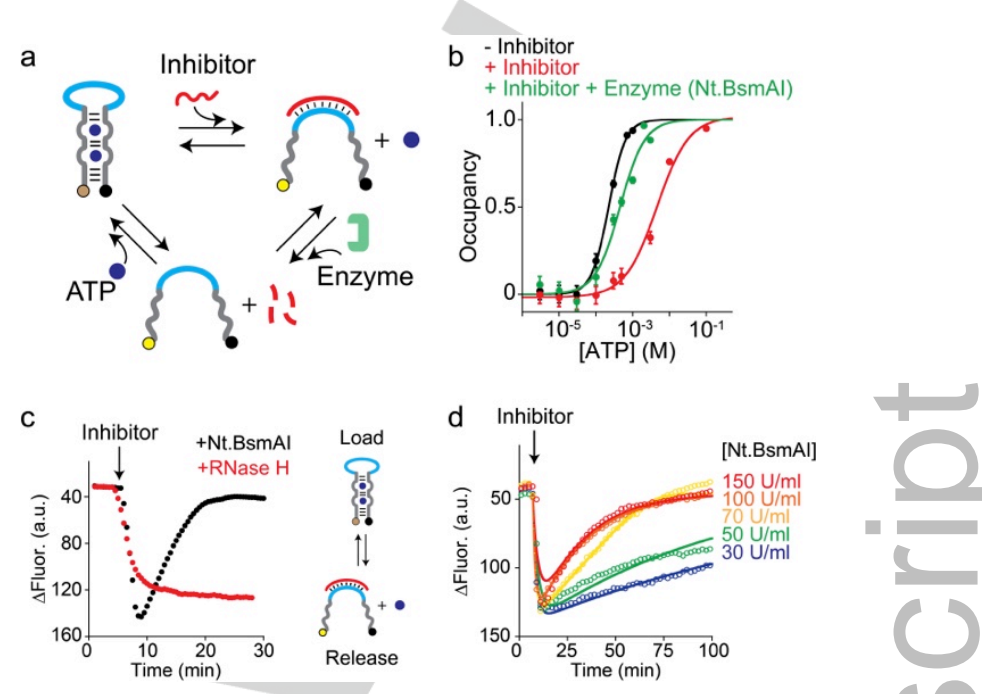

Figure 2. (a) A split ATP-binding aptamer (grey/blue strand) is used here as the receptor. The DNA inhibitor (blue strand) acts as an allosteric inhibitor that triggers the release of ATP. In the presence of Nt.BsmAl, the inhibitor bound to the receptor is selectively hydrolyzed leading to the re-loading of ATP to the receptor. (b) Binding curves of the receptor/ATP interaction in the absence (black) and presence (red) of equimolar concentration of the inhibitor strand and in the concomitant presence of both inhibitor and Nt.BsmAl enzyme (green). (c) Addition of the inhibitor in the presence of the specific enzyme (Nt.BsmAl) leads to a transient release of ATP (black curve). The same experiment performed in the presence of a non-specific nuclease enzyme demonstrates that the transient release is not observed (red curve). (d) Kinetic traces showing the dissipative release of ATP at different concentrations of $\mathrm{Nt}$.BsmAl. Experiments shown in this figure have been obtained in $50 \mathrm{mM}$ potassium acetate, $20 \mathrm{mM}$ Tris acetate, $10 \mathrm{mM}$ magnesium acetate, 100 $\mu \mathrm{g} / \mathrm{mL}$ BSA, $\mathrm{pH} 7.9$, at $45^{\circ} \mathrm{C}$. Solid lines in panel $\mathrm{d}$ represent the data fitting (see text and SI for more details). Error bars represent standard deviation based on triplicate measurements.

To gain further insight in the transient phenomena, a minimal kinetic model was used to fit the experimental data at varying enzyme and inhibitor concentration. The system can be described by two coupled equilibria that involve the receptor binding to ATP or the DNA inhibitor, and a third enzymatic reaction in which the inhibitor is nicked with a Michaelis-Menten kinetics only when bound to the receptor; overall the enzyme cleaves the inhibitor while restoring the free receptor (Figures S7-9, see the SI section for more details on the model). This minimal model is able to reproduce the experimental observations (Figure 2d, solid lines). In particular, the kinetic constants for ATP release, inhibitor binding and enzymatic activity were optimized. Use of the mean optimized parameters allows to reproduce the experimental data under different experimental conditions semi-quantitatively. Moreover, it is worth noting that it was not necessary to take waste interference into account. The high tolerance of the system to the presence of waste products originates from the multivalent nature of duplex formation and is indeed one of the attractive features of using DNA for developing dissipative systems.

An analysis of the sensitivity of the mean kinetic trace to changing parameters (Figures S10-12) shows that the model operates in a regime in which the double strand of DNA binds to Nt.BsmAl and the inhibitor is rapidly cleaved afterwards. This step regulates the signal decrease. The initial rise of the signal is dictated by the dissociation of ATP from the aptamer. Although this minimal model can effectively describe the observations, it 
cannot be excluded that binding of the inhibitor and ATP release occur in a concerted manner.

The reversibility of the transient load-release of ATP was demonstrated by performing multiple load-release cycles through the repetitive additions of a constant amount of inhibitor $\left(1.5 \times 10^{-8} \mathrm{M}\right.$, Figure 3$)$. It is noted that the kinetics of ATP reloading slightly slow down after each cycle, which likely originates from the limited stability of the enzyme over time (Figure S13). The slight increase in signal change for each new cycle is consistent with the fact that the enzyme activity gradually decreases after each cycle (see sensitivity analysis in Figure S11).
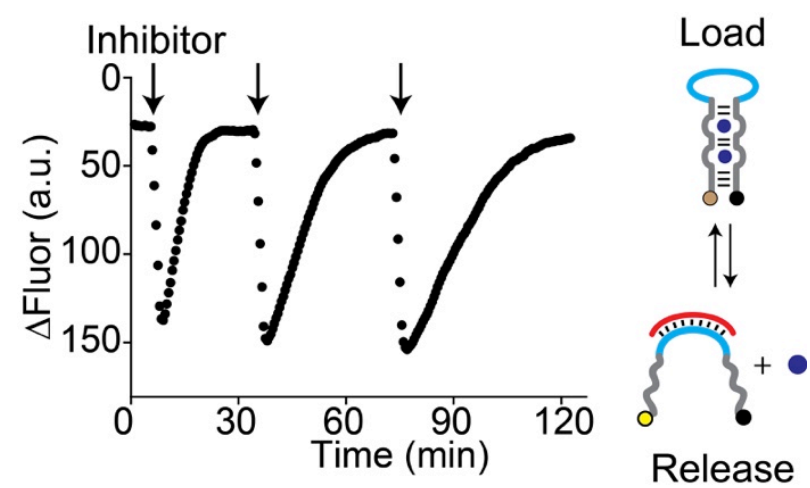

Figure 3. Kinetic traces showing the reversible dissipative release of ATP $(5 x$ $\left.10^{-4} \mathrm{M}\right)$ from the receptor $\left(5 \times 10^{-8} \mathrm{M}\right)$ after sequential addition of the inhibitor strand $\left(1.5 \times 10^{-8} \mathrm{M}\right)$ in the presence of Nt.BsmAl $(100 \mathrm{U} / \mathrm{mL})$. Experiments shown in this figure have been obtained in $50 \mathrm{mM}$ potassium acetate, $20 \mathrm{mM}$ Tris acetate, $10 \mathrm{mM}$ magnesium acetate, $100 \mu \mathrm{g} / \mathrm{mL} \mathrm{BSA}, \mathrm{pH} 7.9$, at $45^{\circ} \mathrm{C}$.

Thanks to the high versatility of DNA as a nanomaterial, this approach can be easily extended to achieve the loading and release of other small molecules, simply by changing the aptamer employed. To demonstrate this, we have used the well characterized cocaine-binding aptamer, which is thought to fold into a three-way junction upon cocaine binding. ${ }^{[35]}$ We have rationally re-engineered this aptamer by introducing at its 3 '-end a DNA sequence that acts as allosteric binding site (Figure 4a). As the inhibitor strand we designed a 18-base DNA sequence complementary to the allosteric site. The binding of the inhibitor to the aptamer receptor leads to unfolding, which triggers the release of cocaine. Also for this system we employed the Nt.BsmAl endonuclease for energy dissipation. This nickase, specifically recognizing the ds-DNA formed between the inhibitor strand and the allosteric binding site of the receptor, can selectively cleave the DNA-inhibitor and restore the capability of the receptor to bind the cocaine. Also in this system, the aptamer was labeled with a fluorophore/quencher-pair to follow the binding of cocaine (Figure 4a).

To demonstrate the dissipative behavior of this new system we performed different time-course experiments in the presence of the specific inhibitor-consuming enzyme and of a non-specific enzyme. Upon the addition of the DNA-inhibitor we observed a signal increase indicating the release of cocaine (Figure $4 \mathrm{~b}$, black curve). Only in the presence of Nt.BsmAl, it is possible to note a signal increase followed by a gradual signal decrease due to the restored capability of the aptamer to re-load cocaine (Figure $4 b$, black curve). Such a decrease in signal was not observed when the experiment was repeated using the nonspecific enzyme RNase-H (Figure 4b, red curve).

Also this new design displays an excellent reversibility and specificity. Multiple load-release cycles, through the repetitive additions of the inhibitor DNA-strand $\left(10^{-8} \mathrm{M}\right)$ in the presence of a fixed concentration of the inhibitor-consuming unit (i.e. the enzyme), demonstrated the possibility to reversible release and load cocaine (Figure 4c).
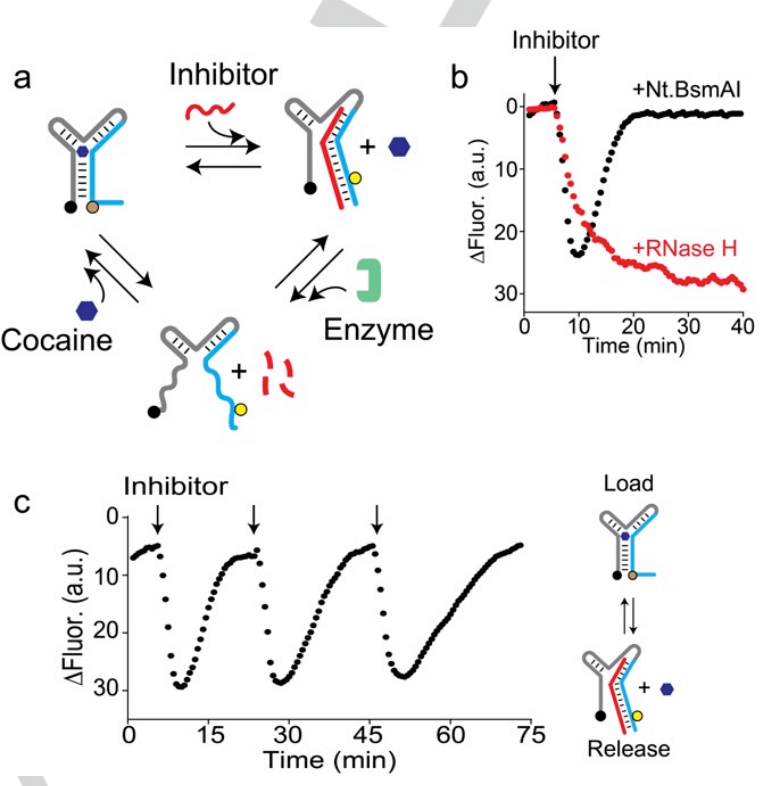

Figure 4. (a) A modified cocaine-binding aptamer (grey/blue strand) is used here as the receptor. The DNA inhibitor (blue strand) acts as an allosteric effector that triggers the release of cocaine. In the presence of Nt.BsmAl, the inhibitor bound to the receptor is selectively hydrolyzed leading to the reloading of cocaine to the receptor. (b) Kinetic traces showing the dissipative release of cocaine from the receptor $\left(10^{-7} \mathrm{M}\right)$ after addition of the inhibitor strand $\left(10^{-8} \mathrm{M}\right)$ and in the presence of a fixed concentration of cocaine $\left(5 \times 10^{-4}\right.$ $\mathrm{M})$ and of the specific (Nt.BsmAl, $500 \mathrm{U} / \mathrm{mL}$ ) and non-specific (RNase-H, 25 $\mathrm{U} / \mathrm{mL}$ ) enzyme. (c) Multiple cycles showing the dissipative release of cocaine from the receptor in a reversible way. Experiments shown in this figure have been obtained in $25 \mathrm{mM}$ potassium acetate, $10 \mathrm{mM}$ Tris acetate, $5 \mathrm{mM}$ magnesium acetate, $50 \mu \mathrm{g} / \mathrm{mL} \mathrm{BSA}, \mathrm{pH} 7.9$, at $45^{\circ} \mathrm{C}$.

In summary, we have demonstrated the rational design of allosteric DNA nanodevices that can transiently release ATP and cocaine upon the addition of a chemical trigger under dissipative conditions. Numerous papers have been reported to date that contain aptamer-based allosteric systems. ${ }^{[28-32]}$ However, to the best of our knowledge, these allosteric aptamers operate under straightforward thermodynamic control. Several related aptamersystems were also recently described which exploit enzymes. [36,37] Although similar at first sight to our transient aptamers, these systems operate in a different way as they achieve switching between two thermodynamic states (binding and nonbinding) by sequential additions of fuel and enzyme, respectively. The novelty of the systems described in our manuscript is that displacement experiments are carried out under dissipative conditions. ${ }^{[21]}$ This implies that the allosteric effector is gradually consumed by an enzyme that is present in the system. Importantly, after consumption of the added effector, the aptamer returns to the original state and the addition of a new allosteric effector can initiate a new cycle. Contrary to the other allosteric systems described so far, the return to the initial state is spontaneous. Our approach thus allows transient allosteric control over a receptor, which is not possible using the analogous systems reported previously. We believe that this strategy will turn out to be essential for the selective, transient 
activation of signaling pathways in synthetic mixtures by specific chemical cues.

The possibility to control small molecules expands the scope of dissipative DNA-based systems beyond nucleic acids. ${ }^{[17]}$ The obtained results demonstrate how the versatility, programmability and predictability of nucleic acid recognition make synthetic DNA/RNA the perfect material for designing nonequilibrium nanoscale systems that can recognize different molecular ligands. An additional advantage is the high tolerance against waste products, which permits high reversibility over several cycles without significant loss of efficiency. Moreover, the present work demonstrates the complete selectivity towards enzymatic cleavage. This provides a way to obtain selective transient allosteric control over a receptor, which is an important prerequisite for the selective activation of signaling pathways in synthetic mixtures with a complexity similar to that observed in nature.

\section{Experimental Section}

Experimental details in supporting information.

Keywords: DNA nanotechnology · Aptamers · DNA devices ·

Dissipative Self-assembly $\cdot$ Supramolecular chemistry $\cdot$ Temporal control
[28] X. Cong, M. Nilsen-Hamilton. Biochemistry 2005, 44, 7945-7954.

[29] J.L. Vinkenborg, N. Karnowski, M. Famulok, Nat. Chem. Biol. 2011, 7, 519-527.

[30] M.N. Stojanovic, D.M. Kolpashchikov, J. Am. Chem. Soc. 2004, 126, 9266-9270.

[31] A. Porchetta, A. Vallée-Bélisle, K.W. Plaxco, F. Ricci, J. Am. Chem. Soc. 2012, 134, 20601-20604.

[32] J. Elbaz, M. Moshe, I. Willner, Angew. Chem. Int. Ed. 2009, 48, 38343837.

[33] D. E. Huizenga, J. W. Szostak, Biochemistry 1995, 34, 656-665.

[34] Z. Zhang, O. Oni, J. Liu, Nucl. Ac. Res. 2017, 45, 7593-7601.

[35] M. B. Stojanovic, P. de Prada, D. W. Landry, J. Am. Chem. Soc. 2001, 123, 4928-4931.

[36] Z. Zhang, D. Balogh, F. Wang, S.Y. Sung, R. Nechushtai, I. Willner, ACS Nano, 2013, 7, 8455-8468.

[37] F. Wang, C.-H. Lu, I. Willner, Chem. Rev. 2014, 114, 2881-2941.

[1] B. A. Grzybowski, W. T. S. Huck, Nat. Nanotechnol. 2016, 11, 585-592.

[2] R. Merindol, A. Walther, Chem. Soc. Rev. 2017, 46, 5588-5619.

[3] E. Te Brinke, J. Groen, A. Herrmann, H. A. Heus, G. Rivas, E. Spruijt, W. T. S. Huck, Nat. Nanotechnol. 2018, 13, 849-855.

[4] J. Boekhoven, A. M. Brizard, K. N. Kowlgi, G. J. Koper, R. Eelkema, J. H. van Esch, Angew. Chem. Int. Ed. 2010, 49, 4825-4828.

[5] A. K. Dambenieks, P. H. Q. Vu, T. M. Fyles, Chem. Sci. 2014, 5, 33963403.

[6] J. Boekhoven, W. Hendriksen, G. Koper, R. Eelkema, J. van Esch, Science 2015, 349, 1075-1079.

[7] S. Maiti, I. Fortunati, C. Ferrante, P. Scrimin, L. J. Prins, Nat. Chem. 2016, 8, 725-731.

[8] C. S. Wood, C. Browne, D. M. Wood, J. R. Nitschke, ACS Cent. Sci. 2015, 1, 504-509.

[9] S. Dhiman, A. Jain, S. J. George, Angew. Chem. Int. Ed. 2017, 56, 1329-1333.

[10] S. Dhiman, A. Jain, M. Kumar, S. J. George, J. Am. Chem. Soc. 2017, 139, 16568-16575.

[11] S. Erbas-Cakmak, S. P. D. Fielden, U. Karaca, D. A. Leigh, C. T. McTernan, D. J. Tetlow, M. R. Wilson, Science 2017, 358, 340-343.

[12] M. Tena-Solsona, B. Rie $\beta$, R. K. Grotsch, F. C. Lohrer, C. Wanzke, B. Kasdorf, A. R. Bausch, P. Muller-Buschbaum, O. Lieleg, J. Boekhoven, Nat. Commun. 2017, 8, 15895.

[13] A. Sorrenti, J. Leira-Iglesias, A. Sato, T. M. Hermans, Nat. Commun. 2017, 8, 15899.

[14] A. Mishra, D. B. Korlepara, M. Kumar, A. Jain, N. Jonnalagadda, K. K. Bejagam, S. Balasubramanian, S. J. George, Nat. Commun. 2018, 9 , 1295.

[15] C. Pezzato, L. J. Prins, Nat. Commun. 2015, 6, 7790.

[16] F. della Sala, S. Maiti, A. Bonanni, P. Scrimin, L. J. Prins, Angew. Chem. Int. Ed. 2018, 130, 1611-1615.

[17] E. Del Grosso, A. Amodio, G. Ragazzon, L. J. Prins, F. Ricci, Angew. Chem. Int. Ed. 2018, 57, 10489-10493.

[18] C. Pezzato, L. J. Prins, Nat. Commun. 2015, 6, 7790.

[19] A. Sorrenti, J. Leira-Iglesias, A. J. Markvoort, T. F. A. de Greef, T. M. Hermans, Chem. Soc. Rev. 2017, 46, 5476-5490.

[20] S. De, R. Klajn, Adv. Mater. 2018, 30, 1706750.

[21] G. Ragazzon, L. J. Prins, Nat Nanotechnol. 2018, 10, 882-889.

[22] P. Solis Muñana, G. Ragazzon, J. Dupont, C. Ren, J. Chen, L. J. Prins, Angew. Chem. Int. Ed. 2018, doi: 10.1002/anie.201810891.

[23] S. Kassem, T. van Leeuwen, A.S. Lubbe, M.R. Wilson, B.L. Feringa, D. A. Leigh, Chem. Soc. Rev. 2017, 46, 2592-2621.

[24] R. Nussinov, C. Tsai, B. Ma, Annu. Rev. Biophys. 2013, 42, 169-189.

[25] M. Perutz, Mechanisms of Cooperativity and Allosteric Regulation in Proteins. Cambridge University Press, Cambridge, U.K. 1990.

[26] M. Famulok, J. S. Hartig, G. Mayer, Chem. Rev. 2007, 107, 3715-3743.

[27] A. D. Keefe, S. Pai, A. Ellington, Nat. Rev. Drug Discov. 2010, 9, 537 550. 


\section{Entry for the Table of Contents}

\section{COMMUNICATION}
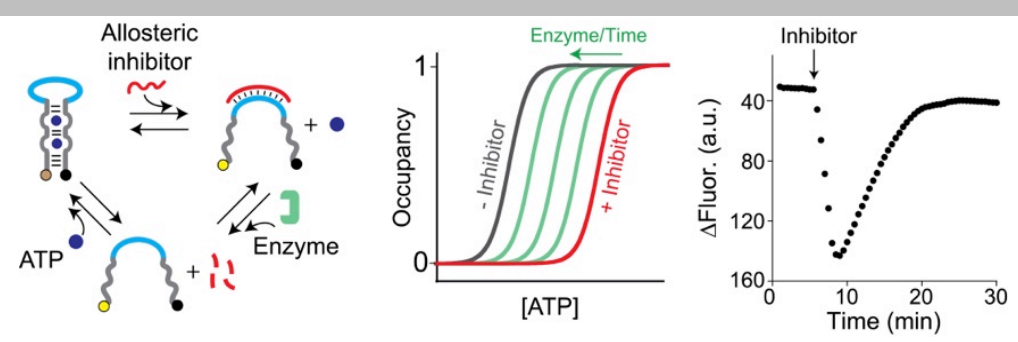

E. Del Grosso , G. Ragazzon, L. Prins*,

F. Ricci*

Page No. - Page No.

Fuel-responsive allosteric DNA-based aptamers for the transient release of ATP and cocaine 